\title{
Formation and Fragmentation of Radical Peptide Anions: Insights from Vacuum Ultra Violet Spectroscopy
}

\author{
Claire Brunet, ${ }^{1,2}$ Rodolphe Antoine, ${ }^{1,2}$ Philippe Dugourd, ${ }^{1,2}$ Francis Canon, ${ }^{3}$ \\ Alexandre Giuliani, ${ }^{3,4}$ Laurent Nahon ${ }^{3}$ \\ ${ }^{1}$ Université de Lyon, F-69622 Lyon, France \\ ${ }^{2}$ Université Lyon 1, Villeurbanne; CNRS, UMR5579, LASIM, Lyon, France \\ ${ }^{3}$ SOLEIL, St Aubin, BP48, 91192 Gif sur Yvette Cedex, France \\ ${ }^{4}$ INRA, U1008, CEPIA, Rue de la Géraudière, BP 71627, 44316 Nantes, France
}

\begin{abstract}
We have studied the photodissociation of gas-phase deprotonated caerulein anions by vacuum ultraviolet (VUV) photons in the 4.5 to $20 \mathrm{eV}$ range, as provided by the DESIRS beamline at the synchrotron radiation facility SOLEIL (France). Caerulein is a sulphated peptide with three aromatic residues and nine amide bonds. Electron loss is found to be the major relaxation channel at every photon energy. However, an increase in the fragmentation efficiency (neutral losses and peptide backbone cleavages) as a function of the energy is also observed. The oxidized ions, generated by electron photodetachment were further isolated and activated by collision (CID) in a $\mathrm{MS}^{3}$ scheme. The branching ratios of the different fragments observed by CID as a function of the initial VUV photon energy are found to be independent of the initial photon energy. Thus, there is no memory effect of the initial excitation energy on the fragmentation channels of the oxidized species on the time scale of our tandem MS experiment. We also report photofragment yields as a function of photon energy for doubly deprotonated caerulein ions, for both closed-shell $\left([\mathrm{M}-2 \mathrm{H}]^{2-}\right)$ non-radical ions and open-shell $\left([\mathrm{M}-3 \mathrm{H}]^{2-}\right.$ ) radical ions. These latter ions are generated by electron photodetachment from $[\mathrm{M}-3 \mathrm{H}]^{3-}$ precursor ions. The detachment yield increases monotonically with the energy with the appearance of several absorption bands. Spectra for radical and non-radical ions are quite similar in terms of observed bands; however, the VUV fragmentation yield is enhanced by the presence of a radical in caerulein peptides.
\end{abstract}

Key words: Radicals, Photodissociation, VUV Spectroscopy, Damage, Gas Phase Peptides, Proteins

\section{Introduction}

$\mathrm{O}$ ptical properties of proteins and radical proteins and their relaxation pathways in the VUV range is of

Electronic supplementary material The online version of this article (doi:10.1007/s13361-011-0285-7) contains supplementary material, which is available to authorized users.

Correspondence to: Rodolphe Antoine; e-mail: rantoine@lasim.univ-lyon1.fr fundamental interest to understand the response of biomolecules to radiation and oxidative stresses [1,2], and may also have important applications in analytical sciences [3]. In particular, a better understanding of the different mechanisms involved between the initial excitation event and the experimentally observed fragmentation might allow the development of new strategies for peptide analysis and protein identification.

In UV photodissociation (UVPD, $200 \mathrm{~nm}<\lambda<400 \mathrm{~nm}$ ) and vacuum UV photodissociation (VUVPD, $\lambda<200 \mathrm{~nm}$ ), 
the photon induces an electronic excitation of the peptide. After excitation, direct dissociation in excited states competes with internal conversion to the electronic ground state and with radiative de-excitation. In particular, in UVPD, specific fragmentation channels are detected, namely formation of radical cations following a hydrogen atom loss and $\mathrm{C}_{\alpha}-\mathrm{C}_{\beta}$ bond cleavage fragments $[4,5]$. The above mentioned UV excitations rely on the existence of aromatic amino acids in the peptide sequence. Another approach, which can be generalized to any peptide whatever its sequence, is to use higher photon energy (in the VUV range) to excite not only the aromatic amino acids but also the peptide backbone amides (below $200 \mathrm{~nm}$ ) [6]. In this aim, ArF (193 nm) and $\mathrm{F}_{2}(157 \mathrm{~nm})$ excimer lasers, which provide high photon fluences, short pulses duration, and high repetition rates, have been coupled to mass spectrometers [3]. Both 193 $(6.4 \mathrm{eV})$ and $157 \mathrm{~nm}(7.9 \mathrm{eV})$ VUVPD methods are charge states dependent. That is, both yield mostly $\mathrm{C}_{\alpha}-\mathrm{C}$ bond cleavage for singly protonated species, but both generate very abundant $\mathrm{b} / \mathrm{y}$-type ions for multiply-charged precursors; $157 \mathrm{~nm}$ generally produces higher abundance $\mathrm{x}$-ions compared with $193 \mathrm{~nm}$, but both methods yield similar a-, $\mathrm{v}-$, and $\mathrm{w}$ - products [7-10]. What is going on at much higher energy is an unexplored field.

Most of photodissociation experiments were first performed on peptide cations, while the interest in negative ions is growing due to the need of techniques suitable for acidic proteins, nucleic acids, or acidic sugars. This led to the development of negative electron transfer dissociation (NETD) [11-15], electron detachment dissociation (EDD) [16-18], and electron photodetachment dissociation (EPD) [19-22]. For peptide and protein polyanions, electron photodetachment is the main relaxation channel observed following UV excitation [23, 24]. For peptides that contain natural aromatic amino-acids (i.e., tryptophan, tyrosine and, in a lesser extent, phenylalanine), absorption at $\sim 260 \mathrm{~nm}$ is mainly due to a resonant electronic excitation $\left(\pi-\pi^{*}\right.$ transition) [24, 25], followed by electronic reorganization and electron emission. This results in the production of radical species with low excess internal energy. The oxidized species can be isolated and further activated by collisions (activated-EPD) [19, 21]. In the case of peptides, the subsequent CID of the isolated radical anions results in intense backbone cleavages. Activated-EPD fragmentation patterns are characterized, for small peptides, by dominant backbone cleavage of $\mathrm{C}_{\alpha}-\mathrm{C}$ bonds giving $a$ and $x$-type product ions [19]. For larger peptides, fragment ions originating from $\mathrm{N}-\mathrm{C}_{\alpha}$ and $\mathrm{C}_{\alpha}-\mathrm{C}$ backbone cleavages are also observed [21]. VUV excitation $(\lambda<200 \mathrm{~nm})$ may open new pathways for electron loss and/or fast dissociation products [8]. The excitation of inner-valence electrons is possible and has still to be explored on fundamental and analytical points of view. Furthermore, as the photon energy increases, a large excess energy can be deposited in the oxidized product leading to the formation of hot radical ions that may relax by a subsequent fragmentation or second electron emission without further excitation, which is not observed at low photon energy $(\mathrm{h} v \sim 4.6 \mathrm{eV})$. In particular, very recently the group of Brodbelt has implemented 193$\mathrm{nm}$ ultraviolet photodissociation (UVPD) to sequence singly and multiply charged peptide anions. Upon dissociation by this method, $a-/ x$-type, followed by $\mathrm{d}$ and w side-chain loss ions, were the most prolific and abundant sequence ions, often yielding $100 \%$ sequence coverage [26].

In this paper, we aim at rationalizing the optical absorption and the relaxation processes that occur in peptide as well as in radical peptide anions following absorption of photons in the 4.5 to $20 \mathrm{eV}$ VUV range, using the synchrotron radiation (SR). The present study focuses on caerulein peptide anions, which have been studied with a large array of dissociation techniques [16, 27-29]. Caerulein (pEQDY $\left(\mathrm{SO}_{3} \mathrm{H}\right)$ TGWMDF-NH${ }_{2}$ ) is sulphated at the $\mathrm{Tyr}_{4}$ residue. Additionally, it has one tryptophan and one phenylalanine aromatic residue as well as nine amide bonds. Caerulein is thus a model peptide for VUV photodissociation experiments since it possesses an extremely labile Osulfation group and numerous aromatic amino-acids and amide bonds. In particular, we aim at studying the influence of the initial electronic excitation on electron detachment and peptide fragmentation patterns. We also question the influence of the initial excitation on the reactivity of oxidized product observed after electron photodetachment. High-energy activation of radical peptides following electron detachment is a totally unexplored field that may lead to new fragmentation patterns. In the last part of this article, we present the VUV spectroscopy of caerulein radical peptides obtained by a two-color experiment using a fixed-wavelength UV laser to photogenerate the radicals and the synchrotron radiation to record their VUV optical spectra.

\section{Materials and Methods}

\section{Materials}

Caerulein, melittin, and bovine insulin were purchased from Sigma-Aldrich (Saint Quentin Fallavier, France). Peptides were dissolved in 50/50 water/acetonitrile ( $\mathrm{vol} / \mathrm{vol}$ ) at a concentration of $12 \mu \mathrm{M}$ and directly electrosprayed at a flow rate of $5 \mu \mathrm{L} / \mathrm{min}$ for subsequent analysis in a negative-ion mode.

\section{Mass Spectrometry and VUV Electron Photodetachment Dissociation}

The experimental setup is based upon a linear ion-trap mass spectrometer (LTQ XL, Thermo Electron, San Jose, CA, USA) coupled to the DESIRS beamline [30] of the SOLEIL synchrotron radiation facility (France) to perform action spectroscopy in the VUV range (see Figure 1). VUVPD and action spectroscopy experiments were performed by illuminating trapped ions with the synchrotron radiation directly injected on the axis of the linear ion trap [31]. A 


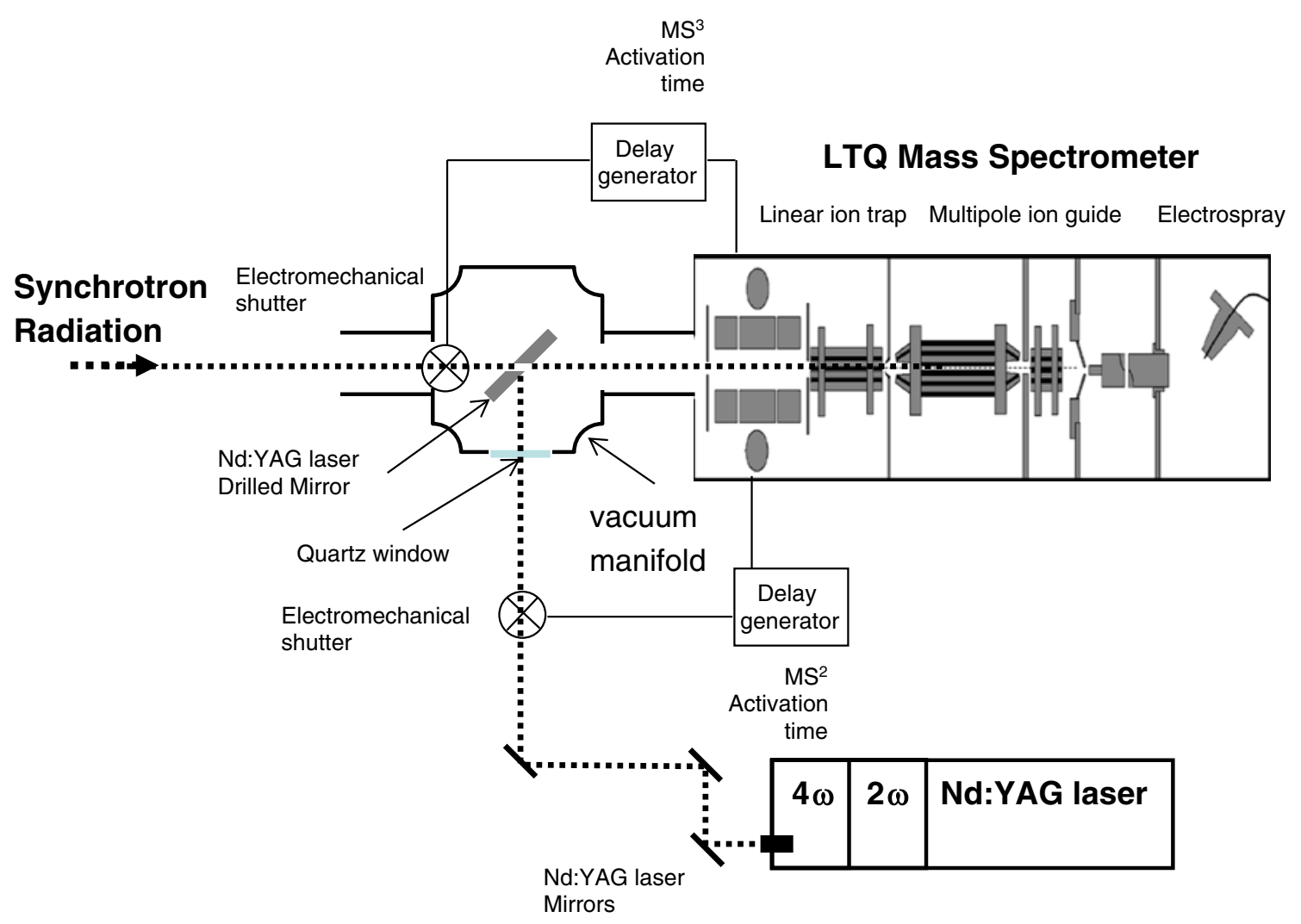

Figure 1. Experimental setup based upon a linear ion-trap mass spectrometer coupled to a UV laser and a VUV synchrotron source radiation beamline within a two-color scheme

differentially-pumped transfer line allows the coupling of the ion trap instrument to the ultra-high vacuum of the beamline. An $\mathrm{MgF}_{2}$ windows (below $9 \mathrm{eV}$ ) and an Ar-filled gas filter $(8-16 \mathrm{eV})$ [32] were used in order to suppress the high harmonics of the ondulator that would be transmitted by the monochromator's grating, fixed at the first order, leading to a $12 \mathrm{meV}$ bandwidth (at $10 \mathrm{eV}$ ) harmonic-free radiation that was sent onto the sample. In complement to VUV action spectroscopy, action spectroscopy between 4 and $5.6 \mathrm{eV}$ was also performed using a quadrupole linear ion trap (LTQ; Thermo Fisher Scientific, San Jose, USA) coupled to a UVVis tunable laser OPO as described previously [21, 33]. CID experiments were performed with the LTQ apparatus.

To assess the reactivity and optical properties of radical peptide anions, we also combined a laser $\left(\mathrm{Nd}^{3+}: \mathrm{YAG}\right.$ laser, time duration $5 \mathrm{~ns}$, fourth harmonic $\lambda=266 \mathrm{~nm}$, repetition rate $20 \mathrm{~Hz}, 20 \mathrm{~mJ} /$ pulse), and the synchrotron source within a two-color scheme, as displayed in Figure 1. The two photon beams were spatially combined via a drilled-coated mirror located $\sim 30 \mathrm{~cm}$ upstream of the ion trap entrance. The UV laser light was reflected at $90^{\circ}$ by the coated mirror and injected collinearly to the axis of the ion trap. The SR beam was injected along the same ion trap axis passing through a $2 \mathrm{~mm}$ diameter hole drilled at the center of the coated mirror.

For VUV photodissociation experiments, the precursor parent ions were selected and irradiated by the SR for $400 \mathrm{~ms}$. To characterize the reactivity and optical spectra of radical species, we also report on activated-EPD experiments (MS ${ }^{3}$ experiments). For collisional activation of the radical species, the precursor parent ions were first selected (MS), irradiated by the UV laser with eight laser shots or by the $\mathrm{SR}$, then the photogenerated radical ions were isolated during the $\mathrm{MS}^{2}$ stage (which typically takes a few tens of milliseconds) and, after isolation, activated by collision. For VUV irradiation of oxidized product, the collisional activation was replaced by SR illumination. Two electromechanical shutters, electronically synchronized with the mass spectrometer, were placed along the laser and SR beams and allowed to inject the laser light and the SR beam on a given time sequence.

\section{Results and Discussion}

\section{VUV Electron Detachment on Polypeptide Ions}

Several peptides anions were subjected to VUV irradiation at $16 \mathrm{eV}$. Figure 2 displays mass spectra obtained following $400 \mathrm{~ms}$ of VUV irradiation at $16 \mathrm{eV}$ for caerulein, melittin and insulin (sequence given in Supporting Information) polypeptide anions. For the three polypeptides, the main photon-induced process appears to be the production of the oxidized ions generated by electron photodetachment from the precursor ion. The electron photodetachment efficiency increases with the size of the polypeptide. This has to be 


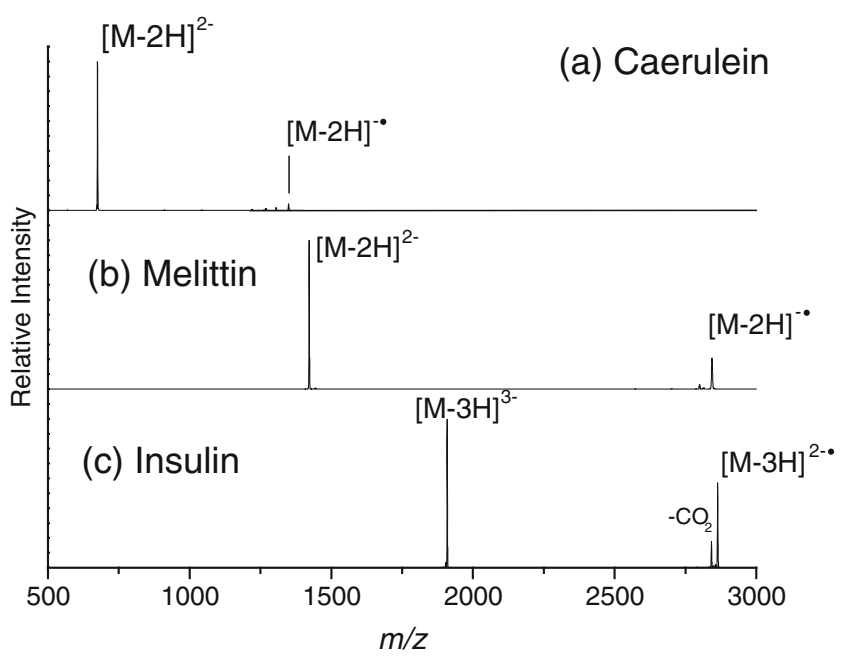

Figure 2. Mass spectra obtained after VUV irradiation at $16 \mathrm{eV}$ of the doubly deprotonated caerulein $\left(\mathrm{pEQDY}\left(\mathrm{SO}_{3} \mathrm{H}\right)\right.$ TGWMDF-NH $\mathrm{N}_{2}$ ) (a), melittin (GIGAVLKVLTTGLPALISWIKRKRQQ-NH $\mathrm{N}_{2}$ (b), and triply deprotonated insulin (c) polypeptides. The irradiation time was $400 \mathrm{~ms}$

correlated to the increase in the density of states in the VUV range, due to the increase in the number of atoms in the system. In the following, we focus on the caerulein peptide. The mass spectra obtained following VUV irradiation at 6 and $19.8 \mathrm{eV}$ of the doubly deprotonated caerulein peptide are shown in Figure $3 \mathrm{a}$ and $\mathrm{b}$. The main photon-induced process appears to be the production of $[\mathrm{M}-2 \mathrm{H}]^{-}$ions $(\mathrm{m} / \mathrm{z}$ 1349) generated by electron photodetachment from the [M$2 \mathrm{H}]^{2-}$ precursor ion. This fragmentation pattern is totally different from what is observed after collisional excitation of the close-shell ion (i.e., $[\mathrm{M}-2 \mathrm{H}]^{2-}$ ), where the spectrum

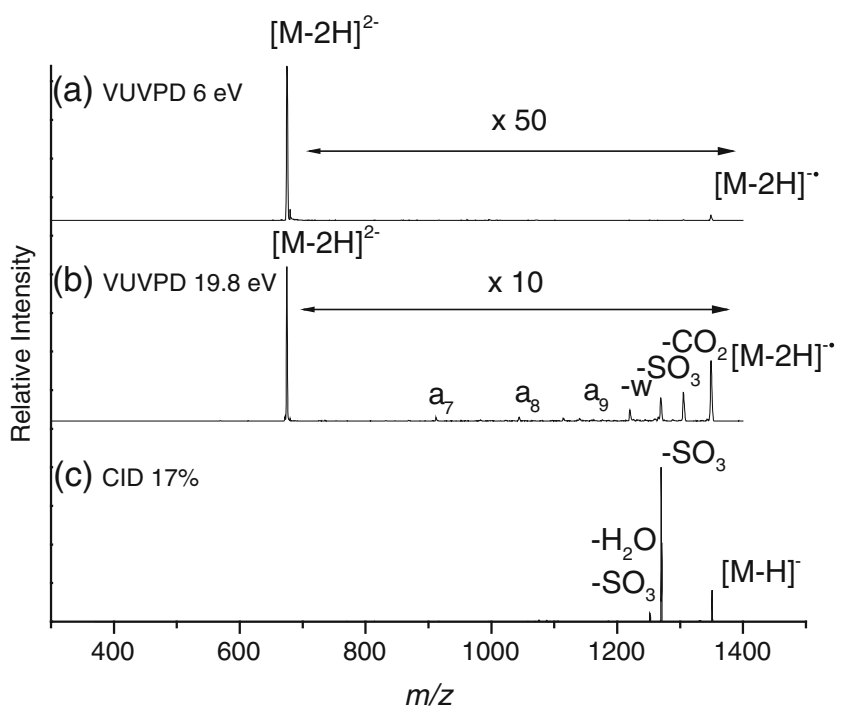

Figure 3. (a) and (b) VUV photodissociation spectra recorded for doubly deprotonated $[\mathrm{M}-2 \mathrm{H}]^{2-}$ caerulein peptide anions respectively for photon energy of 6 and $19.8 \mathrm{eV}$. (c) CID spectrum of singly deprotonated $[\mathrm{M}-\mathrm{H}]^{-}$ caerulein peptide anions at $17 \%$ of collision energy for $30 \mathrm{~ms}$ (see Figure S1) is dominated by small neutral losses. While the electron photodetachment is the only observed channel at $h v=6 \mathrm{eV}$, numerous fragment ions are observed at $h v \sim$ $20 \mathrm{eV}$. Similar results are obtained with melittin polypeptide dianions (see Figure S2 in Supporting Information). For caerulein, these fragments are singly charged and correspond to (1) small neutral losses from the oxidized $[\mathrm{M}-2 \mathrm{H}]^{-}$species, i.e., $-\mathrm{CO}_{2}$ and $-\mathrm{SO}_{3}$ groups, (2) a loss of $129 \mathrm{Da}(-\mathrm{W})$, which corresponds to the side-chain loss of the neutral tryptophan radical, and (3) $a$ - type product ion series (in particular $a_{7}$ ) due to the backbone cleavages (see Scheme 1). Most fragment ions retained the sulphate group.

The loss of $129 \mathrm{Da}$ and the formation of $a_{7}$ ions may be both explained by the formation of a $\operatorname{Trp}^{*}$ radical. The presence of the radical on the nitrogen atom of the indole residue increases the possibility to form $a$ ions between the tryptophan and methionine residues [28, 34]. The most intense fragments discussed above (losses of $\mathrm{CO}_{2}, \mathrm{SO}_{3}$, $129 \mathrm{Da}$ and $a_{7}$ fragment ions) are then thought to originate from a charge loss on the $\mathrm{CO}_{2}{ }^{-}$and $\mathrm{SO}_{3}{ }^{-}$followed either by loss of $-\mathrm{CO}_{2}$ and $-\mathrm{SO}_{3}$ molecules or by radical formation on tryptophan. The latter may be also due to the direct ionization of the tryptophan side chain which is possible at $\mathrm{h} v=20 \mathrm{eV}$. Similarly, backbone fragmentation may originate from direct ionization of peptide bonds as recently suggested by Breuker and colleagues in EDD experiments [34]. Figure 4 displays the branching ratios $\left(B r=\frac{F i}{\sum_{i} F i}\right)$ of the different fragments as a function of the photon energy. As already mentioned, electron loss is the major relaxation channel over the studied photon energy range. Fragmentation efficiency globally increases as the photon energy increases. Moreover, the appearance energies for $[\mathrm{M}-2 \mathrm{H}$ $\left.-\mathrm{CO}_{2}\right]^{-},\left[\mathrm{M}-2 \mathrm{H}-\mathrm{SO}_{3}\right]^{-}$, and $[\mathrm{M}-2 \mathrm{H}-129]^{-}$are different (i.e., 5.5, 7, and $9.5 \mathrm{eV}$, respectively). Backbone cleavages were only observed for photon energies above $\sim 10 \mathrm{eV}$. Assuming that the electron is ejected from the same group (carboxylate group is the group for which the electron affinity $\sim 3.25 \mathrm{eV}$ [35] is the lowest) whatever the VUV photon, these thresholds may be directly related to the binding energy required to open the different fragmentation pathways. The electron would be ejected from the carboxylate group, and the $\mathrm{CO}_{2}$ loss would be the lowest energy dissociation channel. On the other hand, $\mathrm{SO}_{3}$ loss, Trp loss and peptide bond cleavage would require higher energies due to the need for radical migration. Another hypothesis is the possibility to detach electrons from different sites as the photon energy increases. The energy dependence of branching ratios after VUV irradiation may then be correlated to the ionization potential of different groups of the peptide chain. Indeed, while at $4.6 \mathrm{eV}$, a priori only the lowest bound electron localized on the carboxylate group can be photodetached, different chemical groups can be ionized at higher energy. Indeed, the electron affinity of the sulfate group (EA $\left(\mathrm{HSO}_{4}{ }^{-}\right)=4.7 \mathrm{eV} \mathrm{[36])}$ is $\sim 1.5 \mathrm{eV}$ higher than the one of the 


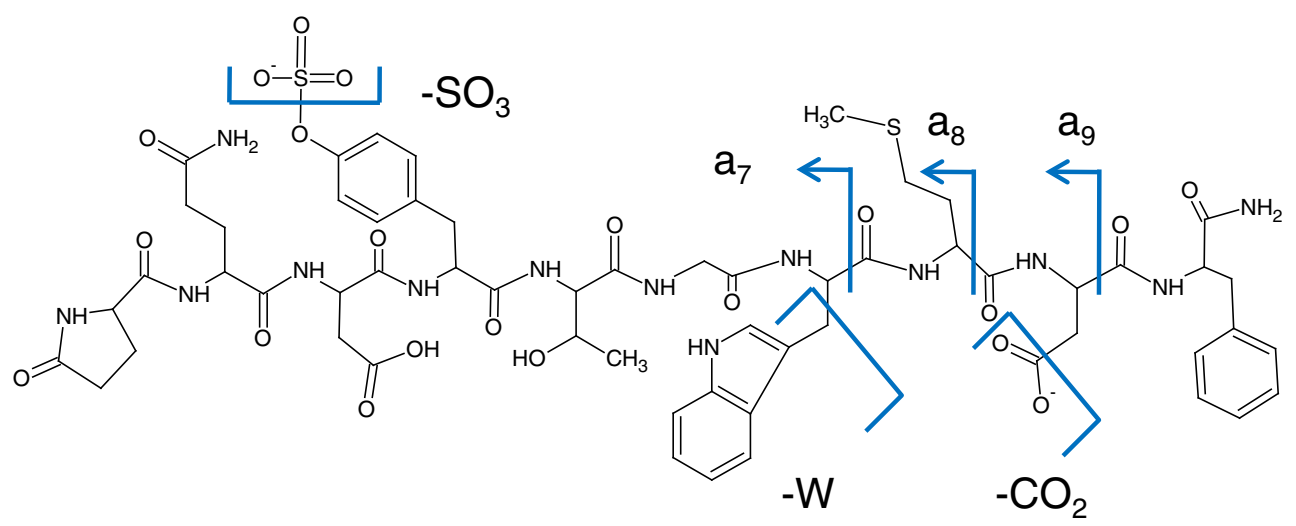

Scheme 1. Structure of caerulein ( $\left.\mathrm{pEQDY}\left(\mathrm{SO}_{3} \mathrm{H}\right) \mathrm{TGWMDF}-\mathrm{NH}_{2}\right)$. The fragments obtained following VUV irradiation of the doubly deprotonated caerulein peptide ions are displayed

carboxylate group $\left(\mathrm{EA}\left(\mathrm{CH}_{3} \mathrm{CO}_{2}^{-}\right)=3.25 \mathrm{eV}\right.$ [35]). This is roughly the energy difference that is observed between the $\mathrm{CO}_{2}$ and $\mathrm{SO}_{3}$ loss appearance energies (i.e., $5.5 \mathrm{eV}$ versus $7 \mathrm{eV}$ ). Thus, the difference between the $\mathrm{CO}_{2}$ and $\mathrm{SO}_{3}$ loss appearance energies could originate from a charge loss from $\mathrm{CO}_{2}{ }^{-}$or $\mathrm{SO}_{3}{ }^{-}$. In the same way, further increase in energy would allow the ionization of the indole residue and of the peptide bond accounting for the tryptophan side chain and the formation of $a$ - type product ion series. Indeed, ionization energies for tryptophan and aromatic amino-acid containing peptides were measured at 7.3 and $9.1 \mathrm{eV}$, respectively [37]. Fragmentation of the peptide would then occur close to the initial position of the radical owing to excess energy let in the peptide. Fragmentation at different parts of the peptide may also result from different electronic excitation on the peptides as a function of the photon energy (see VUV action spectroscopy on doubly deprotonated caerulein $[\mathrm{M}-2 \mathrm{H}]^{2-}$ ions section), while in this case one would expect to observe resonances in the fragmentation channel instead of threshold (see Figure S4).

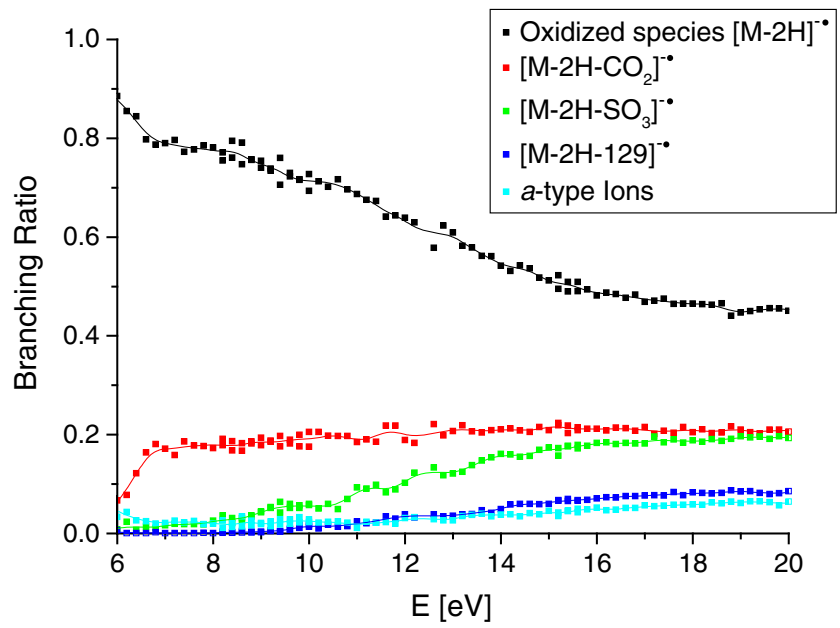

Figure 4. Branching ratios of the different fragments $F_{i}$ as a function of the VUV photon energy for doubly deprotonated $[\mathrm{M}-2 \mathrm{H}]^{2-}$ caerulein peptide anions
In order to get a deeper insight into these fragmentation processes, we performed $\mathrm{MS}^{3}$ experiments. In these experiments, $[\mathrm{M}-2 \mathrm{H}]^{-}$ions were generated by electron VUVphotodetachment of the $[\mathrm{M}-2 \mathrm{H}]^{2-}$ precursor ions. The oxidized $[\mathrm{M}-2 \mathrm{H}]^{-}$ions were further isolated and activated by collision in a second stage. In the first set of experiments, we photodetached at $266 \mathrm{~nm}$ and varied the collision energy (see Supplement Material, Figure S3). All the fragments appear roughly at the same collision energy (from $15 \%$ of collision energy). In the second set of experiments, we set the collision energy at $12 \%$ (in the second stage) and varied the energy of the initial photon (in the first stage). The branching ratios of the different fragments observed by CID as a function of the initial VUV photon energy are plotted in Figure 5. They appear to be independent of the initial photon

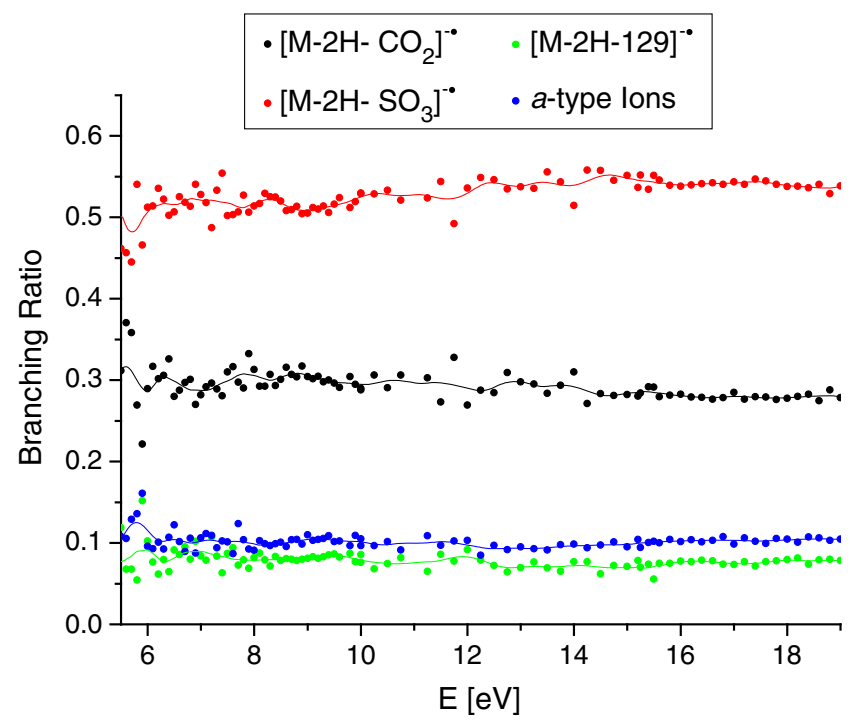

Figure 5. Branching ratios of the different fragments observed by CID of the oxidized $[\mathrm{M}-2 \mathrm{H}]^{-\bullet}$ ions as a function of the initial VUV photon energy. $\mathrm{MS}^{2}$ stage: VUV irradiation of $[\mathrm{M}-2 \mathrm{H}]^{2-}$ ions for $400 \mathrm{~ms}$, and $\mathrm{MS}^{3}$ stage: CID activation of the oxidized $[\mathrm{M}-2 \mathrm{H}]^{\bullet}$ ions at $12 \%$ of collision energy for $30 \mathrm{~ms}$ 
energy. In other words, here, there is no memory of the initial excitation energy in the fragmentation channels of the oxidized species on the time scale of the $\mathrm{MS}^{3}$ experiment. This result may be in favor of an electron expelled from the same site (i.e., $\mathrm{CO}_{2}$ group), whatever the VUV initial photon energy absorbed by the precursor ion. The excess energy is distributed between the internal and the kinetic-energyrelease of the fragments. However, we cannot exclude that in $\mathrm{MS}^{3}$ experiments, collisional excitation may allow radical migration before fragmentation, as recently evidenced [38].

\section{VUV Action Spectroscopy on Doubly Deprotonated Caerulein $[\mathrm{M}-2 \mathrm{H}]^{2-}$ Ions}

To go further in the understanding of photon-induced processes of caerulein peptide, in this part, we explore its optical properties. Figure 6 presents the electron photodetachment efficiency as a function of the wavelength for the doubly deprotonated caerulein peptide anion. The yield of fragmentation $(\sigma)$ was measured as a function of the photon energy $[\sigma=\ln$ (\{parent $+\Sigma$ frag $\} /$ parent $) / \phi]$, where $\phi$ is the photon flux, "parent" stands for the intensity of the parent peak and " $\Sigma$ frag" represents the total intensity of the photofragment peaks). The detachment yield curve shows a strong dependence to the SR energy. Superimposed to a monotonical increase in the electron detachment yield with photon energy, several well-resolved bands are observed, in particular at 4.6, 5.7, and $6.7 \mathrm{eV}$. These bands may be attributed to the $\pi-\pi^{*}$ bands for $\mathrm{S}_{0} \rightarrow \mathrm{S}_{1}, \mathrm{~S}_{2}$, and $\mathrm{S}_{3}$ transitions of phenylalanine, tyrosine, and tryptophan chromophores that are present in this peptide, even if at

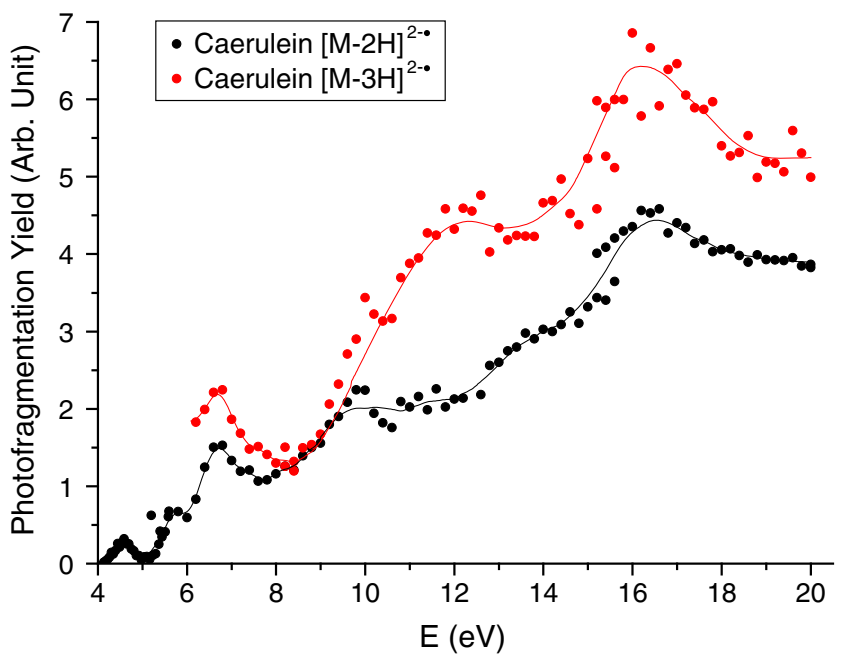

Figure 6. VUV action spectra of doubly deprotonated nonradical $[\mathrm{M}-2 \mathrm{H}]^{2-}$ and radical $[\mathrm{M}-3 \mathrm{H}]^{2-\bullet}$ caerulein peptide anions. The photon energy bandwidth is typically $12 \mathrm{meV}$ at $10 \mathrm{eV}$. The action spectrum was recorded with the linear iontrap LTQ XL mass spectrometer coupled to the DESIRS beamline of the SOLEIL synchrotron center, except between 4 and $5.6 \mathrm{eV}$, where the spectrum was recorded using the LTQ quadrupole linear ion trap coupled to a UV-Vis tunable laser OPO in Lyon
$6.7 \mathrm{eV}$ the peptide bonds play also a role [39]. For energy above $7 \mathrm{eV}$, the increase in absorption is due to excitation of other groups than aromatic rings. The $7.8 \mathrm{eV}$ band was assigned to the absorption of the $\mathrm{COOH}$ group and the increase in absorption from $7.8 \mathrm{eV}$ to $10.3 \mathrm{eV}$ is associated with the excitation of $\sigma$ electrons of the $\mathrm{C}-\mathrm{C}$ and $\mathrm{C}-\mathrm{H}$ bonds [40], as observed for polyamides [41]. The attribution and the nature of the bands observed at $\sim 10 \mathrm{eV}$ and $\sim 16 \mathrm{eV}$, a nearly totally unexplored energy range, is challenging since many electrons in caerulein may contribute to the absorption in the 8-16 eV spectral range. We report here a benchmark spectrum that we hope will stimulate calculations in this energy range.

\section{Comparison with Protonated Peptides}

Here, we want to emphasize that the fragmentation channels observed for caerulein peptide dianions are drastically different from what is reported for protonated peptides. Using F2 lasers (7.9 eV) [8], Reilly and coworkers reported photodissociation of peptide backbone $\mathrm{C}_{\alpha}-\mathrm{C}$ bonds resulting in $a$ - or $x$-ion fragments. They suggest that laser induced fragmentation occurs via a Rydberg excitation (and/or electron detachment mechanism) and subsequent $\mathrm{C}_{\alpha}-\mathrm{C}$ bond cleavage [9]. The ionization potentials of tryptophan and phenylalanine in the gas phase are, respectively, 7.4 and $8.65 \mathrm{eV}$ [42]. Ionization thresholds for neutral polypeptides are, however, slightly higher in energy (around $9.8 \mathrm{eV}$ ) [43]. An increase in absorption above $8-10 \mathrm{eV}$ may be associated with photofragmentation and photoionization processes. Very recently, Schlathölter and coworkers studied photodissociation of protonated leucine-enkephalin (leu-enk) in the VUV range of 8-40 eV. Different regimes of dissociation processes, below and above ionization energy (IE), have to be considered. For $h v<\mathrm{IE}$, fragmentation is governed by IVR, while for $h v>\mathrm{IE}$, the protonated peptide can be photoionized and a protonated leu-enk dication radical is formed, and the tyrosine side chain fragment in addition to immonium ions become the major fragments for photon energies exceeding $10 \mathrm{eV}$ [44]. Note, however, that for multiply protonated proteins, photoionization is the main fragmentation pattern [31]. For peptide polyanions as discussed above, the oxidation of the precursor ion (electron loss) is the dominant relaxation pathway in the 4-20 eV energy range, even if fragment ions are intense at high energy.

\section{VUV Action Spectroscopy on Radical Doubly Deprotonated Caerulein $[\mathrm{M}-3 \mathrm{H}]^{2-\bullet}$ Ions}

Besides the formation and fragmentation of radicals following VUV irradiation by electron photodetachment, it is fundamental to assess the effect of a VUV light on photogenerated radicals formed by environmental stress or radiation. Indeed, under VUV radiation, homolytic cleavages and ionization processes result in free-radical formation, which is one of the major causes of damage or degradation to DNA [45] or proteins [1] following VUV radiation absorption. VUV spectroscopy is a totally unexplored field. 
This is in part due to the difficulty to isolate and characterize radicals under VUV irradiation in solution or in solids. By bringing a system into the gas phase, it is possible to eliminate the shielding of the radiations by the solvent as well as spurious intermolecular and/or solvent-molecule interactions. For this purpose, we recorded the VUV spectroscopy of radical doubly deprotonated caerulein $[\mathrm{M}-3 \mathrm{H}]^{2-\bullet}$ ions by a two-color experiment. We used a fixed-wavelength UV laser to photogenerate the caerulein $[\mathrm{M}-3 \mathrm{H}]^{2 \cdot-}$ radicals (from the triply deprotonated $[\mathrm{M}-3 \mathrm{H}]^{3-}$ caerulein precursor ions) and the synchrotron radiation to record their VUV optical spectra by action spectroscopy. The electron loss (leading to $[\mathrm{M}-3 \mathrm{H}]^{-0}$ ) is the major fragmentation channel at every photon energy (as displayed in supplement material, Figure S4). This product was not observed after CID excitation of the oxidized product [M $3 \mathrm{H}]^{2-\cdot}$ (data not shown). Between 6 and $9 \mathrm{eV}$, abundant fragmentation arises from the side chain loss of tryptophan residue and the formation of $a$ ions (and particularly $a_{7}$ ions). The fragmentation pathways strongly depend on the SR energy, with for example pronounced maxima observed at $12 \mathrm{eV}$ for chain loss of tryptophan residue and $\boldsymbol{a}_{7}$ product. This is different from what was found for the dianion (see Figure 4) and has to be correlated to the action spectrum of the $[\mathrm{M}-3 \mathrm{H}]^{2 \cdot-}$ which is shown in Figure 6. Figure 6 compares the electron photodetachment efficiency as a function of the wavelength for the doubly negatively charged caerulein peptide anions in its radical ([M $\left.3 \mathrm{H}]^{2-}\right)$ and non-radical $\left([\mathrm{M}-2 \mathrm{H}]^{2-}\right)$ forms. The VUV action spectrum is enhanced by the presence of a radical in caerulein peptides, which may be due to a decrease in the stability of the radical anion as compared to the even electron species. Note that an enhancement in photofragmentation yields of radical species by one order of magnitude with respect to non-radical peptides was recently demonstrated for pentapeptide dianions [46]. Bands at 6.5 and $16.3 \mathrm{eV}$ are observed for both species while the intense band at $12 \mathrm{eV}$ is not observed for the non-radical species. While we recently explored the UV optical properties of radical peptides and proteins [47, 48], theoretically and experimentally very few is known on the nature of high energy absorption of radical peptides [46]. Maxima in the branching ratio corresponding to fragmentation (as opposed to electron loss) are correlated to the bands observed at 6 and $12 \mathrm{eV}$. The fragmentation is here directly related to the initial electronic excitation. In particular, intense transitions due mainly to $\pi-\pi^{*}$ transitions are predicted at $\sim 6.7 \mathrm{eV}$ for phenol and at $\sim 6.1 \mathrm{eV}$ for indole [46]. For photon energy higher than $6.2 \mathrm{eV}$, excitations are not only localized on the aromatic amino acid rings but also on the peptide backbone amides [6]. In this case, resonances in the fragmentation pathways are observed (Figure S4) while for VUV excitation of the non radical species only thresholds were observed (Figure 4).

\section{Conclusion}

In summary, the irradiation of vacuum ultraviolet (VUV) photons, with energies ranging from 4.5 to $20 \mathrm{eV}$, on caerulein peptide polyanions leads mainly to an electron loss. Additionally, an increase in the fragmentation efficiency (neutral losses and peptide backbone cleavage) as a function of the energy is observed. The fragmentation pattern observed for the oxidized ions after activation by collisions are found independent of the initial photon energy on the time scale of the $\mathrm{MS}^{3}$ experiment. Thus, there is no memory effect of the initial excitation energy in the fragmentation channels of the oxidized species.

Electron photodetachment yield as a function of photon energy was used to record optical action spectra of deprotonated caerulein ions in the VUV range. Action spectra for both closed-shell $\left([\mathrm{M}-2 \mathrm{H}]^{2-}\right)$ non-radical ions and open-shell $\left([\mathrm{M}-3 \mathrm{H}]^{2-}\right.$ radical ions generated by electron photodetachment from $[\mathrm{M}-3 \mathrm{H}]^{3-}$ precursor ions) were recorded. The detachment yield increases with the photon energy. Several bands are superimposed to this general increase. The nature of the absorption bands in the VUV range is difficult to analyze since many electronic excitations may contribute to these bands. However, these bands constitute benchmarks for calculations. Spectra for radical and non-radical ions are very similar in terms of observed bands; however the VUV action spectrum is enhanced by the presence of a radical in caerulein peptides. This enhanced photofragmentation for radical species may be attributed to a decrease in binding energy for fragmentation channels.

These results are of great interest concerning the radiation damage to biomolecules. Indeed, the sign of the charge state of the peptide leads to drastic different relaxation channels, with in the case of polyanions a de-excitation that proceeds via a universal relaxation channel, i.e., electron loss, preventing the molecular anions from a major fragmentation.

\section{Acknowledgments}

This work is supported by the Agence Nationale de la Recherche Scientifique, France, under the project \#BLAN08-1_348053. SOLEIL support is acknowledged under project \#20100187. The authors are heavily indebted to Jean-François Gil and Aleksandar Milosavljevic for the ion trap frame design and to Jean-François Gil for his help in alignment with respect to the DESIRS beamline. The authors also thank the general technical staff of SOLEIL for running the facility.

\section{References}

1. Davies, M.J., Truscott, R.J.W.: Photo-oxidation of proteins and its role in cataractogenesis. J. Photochem. Photobiol. B Biol. 63, 114-125 (2001)

2. Hawkins, C.L., Davies, M.J.: Generation and propagation of radical reactions on proteins. BBA-Bioenergetics 1504, 196-219 (2001)

3. Reilly, J.P.: Ultraviolet photofragmentation of biomolecular ions. Mass Spectrom. Rev. 28, 425-447 (2009)

4. Oh, J.Y., Moon, J.H., Kim, M.S.: Sequence- and site-specific photodissociation at $266 \mathrm{~nm}$ of protonated synthetic polypeptides containing a tryptophanyl residue. Rapid Commun. Mass Spectrom. 18, 2706-2712 (2004) 
5. Tabarin, T., Antoine, R., Broyer, M., Dugourd, P.: Specific photodissociation of peptides with multi-stage mass spectrometry. Rapid Commun. Mass Spectrom. 19, 2883-2892 (2005)

6. Preiss, J.W., Setlow, R.: Spectra of some amino acids, peptides, nucleic acids, and protein in the vacuum ultraviolet. J. Chem. Phys. 25, 138141 (1956)

7. Barbacci, D.C., Russell, D.H.: Sequence and side-chain specific photofragment $(193 \mathrm{~nm})$ ions from protonated substance $\mathrm{P}$ by matrixassisted laser desorption ionization time-of-flight mass spectrometry. $J$. Am. Soc. Mass Spectrom. 10, 1038-1040 (1999)

8. Thompson, M.S., Cui, W.D., Reilly, J.P.: Fragmentation of singly charged peptide ions by photodissociation at $\lambda=157 \mathrm{~nm}$. Angew. Chem. Int. Edit. 43, 4791-4794 (2004)

9. Parthasarathi, R., He, Y., Reilly, J.P., Raghavachari, K.: New insights into the vacuum UV photodissociation of peptides. J. Am. Chem. Soc. 132, 1606-1610 (2010)

10. Kim, T.Y., Thompson, M.S., Reilly, J.P.: Peptide photodissociation at $157 \mathrm{~nm}$ in a linear ion trap mass spectrometer. Rapid Commun. Mass Spectrom. 19, 1657-1665 (2005)

11. Huzarska, M., Ugalde, I., Kaplan, D.A., Hartmer, R., Easterling, M.L., Polfer, N.C.: Negative electron transfer dissociation of deprotonated phosphopeptide anions: Choice of radical cation reagent and competition between electron and proton transfer. Anal. Chem. 82, 2873-2878 (2010)

12. Huang, T.-Y., Emory, J.F., O'Hair, R.A.J., McLuckey, S.A.: Electrontransfer reagent anion formation via electrospray ionization and collision-induced dissociation. Anal. Chem. 78, 7387-7391 (2006)

13. Coon, J.J., Shabanowitz, J., Hunt, D.F., Syka, J.E.P.: Electron transfer dissociation of peptide anions. J. Am. Soc. Mass Spectrom. 16, 880-882 (2005)

14. Herron, W.J., Goeringer, D.E., McLuckey, S.A.: Gas-phase electron transfer reactions from multiply-charged anions to rare gas cations. $J$. Am. Chem. Soc. 117, 11555 (1995)

15. Wolff, J.J., Leach, F.E., Laremore, T.N., Kaplan, D.A., Easterling, M. L., Linhardt, R.J., Amster, I.J.: Negative electron transfer dissociation of glycosaminoglycans. Anal. Chem. 82, 3460-3466 (2010)

16. Budnik, B.A., Haselmann, K.F., Zubarev, R.A.: Electron detachment dissociation of peptide di-anions: An electron-hole recombination phenomenon. Chem. Phys. Lett. 342, 299-302 (2001)

17. Kinet, C., Gabelica, V., Balbeur, D., De Pauw, E.: Electron detachment dissociation (EDD) pathways in oligonucleotides. Int. J. Mass Spectrom. 283, 206-213 (2009)

18. Wolff, J.J., Laremore, T.N., Aslam, H., Linhardt, R.J., Amster, I.J.: Electron induced dissociation of glycosaminoglycan tetrasaccharides. $J$. Am. Soc. Mass Spectrom. 19, 1449 (2008)

19. Antoine, R., Joly, L., Tabarin, T., Broyer, M., Dugourd, P., Lemoine, J.: Photo-induced formation of radical anion peptides. Electron photodetachment dissociation experiments. Rapid Commun. Mass Spectrom. 21, 265-268 (2007)

20. Gabelica, V., Rosu, F., Tabarin, T., Kinet, C., Antoine, R., Broyer, M., De Pauw, E., Dugourd, P.: Base-dependent electron photodetachment from negatively charged DNA strands upon 260-nm laser irradiation. $J$. Am. Chem. Soc. 129, 4706-4713 (2007)

21. Larraillet, V., Antoine, R., Dugourd, P., Lemoine, J.R.M.: Activatedelectron photodetachment dissociation for the structural characterization of protein polyanions. Anal. Chem. 81, 8410-8416 (2009)

22. Racaud, A., Antoine, R., Dugourd, P., Lemoine, J.: Photoinduced dissociation of heparin-derived oligosaccharides controlled by charge location. J. Am. Soc. Mass Spectrom. 21, 2077 (2010)

23. Joly, L., Antoine, R., Allouche, A.R., Broyer, M., Lemoine, J., Dugourd, P.: Ultraviolet spectroscopy of peptide and protein polyanions in vacuo: signature of the ionization state of tyrosine. J. Am. Chem. Soc. 129, 8428-8429 (2007)

24. Joly, L., Antoine, R., Broyer, M., Lemoine, J., Dugourd, P.: Electron photodetachment from gas phase peptide dianions. relation with optical absorption properties. J. Phys. Chem. A 112, 898-903 (2008)

25. Matheis, K., Joly, L., Antoine, R., Lepine, F., Bordas, C., Ehrler, O.T., Allouche, A.-R., Kappes, M.M., Dugourd, P.: Photoelectron spectroscopy of gramicidin polyanions: competition between delayed and direct emission. J. Am. Chem. Soc. 130, 15903-15906 (2008)

26. Madsen, J.A., Kaoud, T.S., Dalby, K.N., Brodbelt, J.S.: 193-nm photodissociation of singly and multiply charged peptide anions for acidic proteome characterization. Proteomics 11, 1329-1334 (2011)
27. Boontheung, P., Alewood, P.F., Brinkworth, C.S., Bowie, J.H., Wabnitz, P.A., Tyler, M.J.: Negative ion electrospray mass spectra of caerulein peptides: An aid to structural determination. Rapid Commun. Mass Spectrom. 16, 281-286 (2002)

28. Larraillet, V., Vorobyev, A., Brunet, C., Lemoine, J., Tsybin, Y.O., Antoine, R., Dugourd, P.: Comparative dissociation of peptide polyanions by electron impact and photo-induced electron detachment. J. Am. Soc. Mass Spectrom. 21, 670-680 (2010)

29. Liu, H., Håkansson, K.: Electron capture dissociation of tyrosine osulfated peptides complexed with divalent metal cations. Anal. Chem. 78, 7570-7576 (2006)

30. http://www.synchrotron-soleil.fr/portal/page/portal/Recherche/Lignes Lumiere/DESIRS. (2011)

31. Milosavljevic, A.R., Nicolas, C., Lemaire, J., Dehon, C., Thissen, R., Bizau, J.-M., Refregiers, M., Nahon, L., Giuliani, A.: Photoionization of a protein isolated in vacuo. Phys. Chem. Chem. Phys. 13, 15432-15436 (2011)

32. Mercier, B., Compin, M., Prevost, C., Bellec, G., Thissen, R., Dutuit, O., Nahon, L.: Experimental and theoretical study of a differentially pumped absorption gas cell used as a low energy-pass filter in the vacuum ultraviolet photon energy range. J. Vac. Sci. Technol. A Vac. Surf. Films 18, 2533-2541 (2000)

33. Racaud, A., Antoine, R., Joly, L., Mesplet, N., Dugourd, P., Lemoine, J.: Wavelength-tunable ultraviolet photodissociation (UVPD) of heparin-derived disaccharides in a linear ion trap. J. Am. Soc. Mass Spectrom. 20, 1645-1651 (2009)

34. Ganisl, B., Valovka, T., Hartl, M., Taucher, M., Bister, K., Breuker, K.: Electron detachment dissociation for top-down mass spectrometry of acidic proteins. Chem. Eur. J. 17, 4460-4469 (2011)

35. Wang, X.B., Woo, H.K., Wang, L.S., Minofar, B., Jungwirth, P.: Determination of the electron affinity of the acetyloxyl radical $(\mathrm{CH} 3 \mathrm{COO})$ by low temperature. anion photoelectron spectroscopy and ab initio calculations. J. Phys. Chem. A 110, 5047 (2006)

36. Wang, X.B., Nicholas, J.B., Wang, L.S.: Photoelectron spectroscopy and theoretical calculations of SO4- and HSO4-: Confirmation of high electron affinities of SO4 and HSO4. J. Phys. Chem. A 104, 504 (2000)

37. Wilson, K.R., Jimenez-Cruz, M., Nicolas, C., Belau, L., Leone, S.R., Ahmed, M.: Thermal vaporization of biological nanoparticles: fragment-free vacuum ultraviolet photoionization mass spectra of tryptophan, phenylalanine-glycine-glycine, and beta-carotene. J. Phys. Chem. A 110, 2106-2113 (2006)

38. Moore, B.N., Blanksby, S.J., Julian, R.R.: Ion-molecule reactions reveal facile radical migration in peptides. Chem. Commun 5015-5017 (2009)

39. Dodonova, N.Y.: Vacuum UV - photophysics and photochemistry of biomolecules. J. Photochem. Photobiol. B Biol. 18, 111-121 (1993)

40. Inagaki, T.: Optical absorptions of aliphatic amino acids in the far ultraviolet. Biopolymers 12, 1353 (1973)

41. Onary, S.: Vacuum ultraviolet absorption spectraof polyamides. Jpn. J. Appl. Phys. 9, 227 (1970)

42. Gaie-Levrel, F., Garcia, G.A., Schwell, M., Nahon, L.: VUV state-selected photoionization of thermally-desorbed biomolecules by coupling an aerosol source to an imaging photoelectron/photoion coincidence spectrometer: case of the amino acids tryptophan and phenylalanine. Phys. Chem., Chem. Phys 13, 7024-7036 (2011)

43. Budnik, B.A., Tsybin, Y.O., Håkansson, P., Zubarev, R.A.: Ionization energies of multiply protonated polypeptides obtained by tandem ionization in Fourier transform mass spectrometers. J. Mass Spectrom. 37, 1141-1144 (2002)

44. Bari, S., Gonzalez-Magana, O., Reitsma, G., Werner, J., Schippers, S., Hoekstra, R., Schlathölter, T.: Photodissociation of protonated leucineenkephalin in the VUV range of 8-40 eV. J. Chem. Phys. 134, 024314 (2011)

45. Giese, B.: Electron transfer in DNA. Curr. Opin. Chem. Biol. 6, 612$618(2002)$

46. Brunet, C., Antoine, R., Allouche, A.-R., Dugourd, P., Canon, F., Giuliani, A., Nahon, L.: Gas phase photo-formation and vacuum UV photofragmentation spectroscopy of tryptophan and tyrosine radicalcontaining peptides. J. Phys. Chem. A 115, 8933-8939 (2011)

47. Joly, L., Antoine, R., Allouche, A.-R., Dugourd, P.: Formation and spectroscopy of a tryptophan radical containing peptide in the gas phase. J. Am. Chem. Soc. 130, 13832-13833 (2008)

48. Antoine, R., Dugourd, P.: Visible and ultraviolet spectroscopy of gas phase protein ions. Phys. Chem. Chem. Phys. 13, 16494-16509 (2011) 